\title{
CONCEPTUAL BACKGROUND OF THE ESSENTIAL INSTITUTIONALIZATION OF A PHILOSOPHY OF THE BIOINTELLECTOSPHERE
}

Sergei V. Smirnov ${ }^{1}$

Aiziriak N. Tarasova ${ }^{2}$

\begin{abstract}
Under. In this paper, the author characterizes the conceptual foundations of building the philosophy of the bio-elelectic sphere as a theoretical construct, which development will allow revealing the essential aspects of the strategy of rational socio-natural development, determining the directions for its subsequent implementation. "Biotelectectosphere (bios - life, sphaira - sphere, Latin intellectus - intellect) the sphere of intelligent organization of life - the stage of development of the biosphere, where human activity will be aimed at preserving and maintaining the conditions necessary for the optimal existence of life - the geological factor, which is the initial prerequisite for the emergence and existence of mankind
\end{abstract}

Keywords: Anthropic cosmological principle, biointellectosphere, biosphere, Universe, living matter.

\section{Introduction}

A number of studies by Russian scientists and philosophers have been devoted to the problem of developing the conceptual foundations of the strategy of rational socio-natural development. The most important of them are the works by representatives of the noospheric scientific school such as V.I. Vernadskii, N.N. Moiseev, V.P. Kaznacheev, A.D. Ursul, A.I. Subetto and others. In their works they consider evolutionary laws of the formation of the sphere of rational interaction between man (society) and nature (Vernadskii, 2007); problems of cosmoplanetary evolution of man and living matter as elements of a single selfregulating system (Kaznacheev, \&

\footnotetext{
${ }^{1}$ Kazan Federal University, Kazanskaya st, 89, Yelabuga, Republic of Tatarstan.

${ }^{2}$ Kazan Federal University, Kazanskaya st, 89, Yelabuga, Republic of Tatarstan.
} 
Trofimov, 2004 ; Ekinci \& Ozcan, 2017); features of the organization and implementation of managed socionatural evolution on the basis of social intelligence and new forms of the government structure (Subetto, 2001; Abreu et al., 2016).

At the same time, the works by the representatives of the noospheric school treat the strategy of the joint harmonious development of man (society) and nature basically as a process organized and managed by a man. In our opinion, such a vision of this strategy is not entirely justified, since, firstly, it does not take into account the geological significance of living matter as a fundamental factor of geological evolution - the scale of its manifestation in the biosphere is many times greater than that of man; secondly, it excessively hyperbolizes the possibilities of the thinking being as a Part able of "managing" the Whole (Weitzsacker et al., 1997).

These circumstances require the development of a concept that allows us to identify the value of living matter and thinking humanity as factors, which interaction determines the ways of the joint evolution of man (society) and
430

nature. In this study, an attempt is made to solve this problem.

\section{Methods}

The methods used in this paper are as follows:

- dialectical method (attitude to human activity as a factor of rationalization and, at the same time, destabilization of socioenvironmental relations);

- analysis (the identification of principles and laws reflecting the geological significance of mankind and living matter as components of the biosphere, the idea of a person as a participant in the evolutionary processes of the universe, a rational being capable of cognition and rational transformation of nature);

(considering the concept of the biointellectosphere as a category, which is the basis for the essential constitution of the philosophy of the biointellectosphere).

\section{Results}

In accordance with the logic of the creation of the theory, we refer to a conceptual basis for the construction of 
the philosophy of the biointellectosphere a number of principles and laws, which content reflects the geological significance of living and thinking matter as components of the biosphere in many respects, determining the homeostatic parameters of the geographic envelope, the laws of its development and functioning; the idea of a man as a participant in the evolutionary processes of the Universe, a rational being capable of using the methodology of social and humanitarian cognition to the study and rational transformation of nature (Sabirov, 2013; Ranjbar haghighi \& Ghaffari, 2016).

We refer the biogeochemical laws (principles) by V.I. Vernadsky, the environmental laws by B. Commoner, the anthropic cosmological principle, the principle of the Great Cosmological Supplement by V.P. Kaznacheev and A.I. Subetto as the most important of these grounds.

Now we shall consider the listed conceptual bases in more details.

Biogeochemical principles of V.I. Vernadskii reflect ideas about the geological significance of living matter and a man as a part of it.
V.I. Vernadskii's merit is that this thinker for the first time drew attention to the special role of life and living matter in the geological processes taking place on the planet. According to the conclusions of the scientist, living matter largely determines the planet landscape, the composition of rocks, soil, a number of minerals (oil, coal), the chemical structure of the atmosphere and hydrosphere. In his works, V.I. Vernadskii shows that the chemical composition of the earth's crust is due to the processes of biogenic migration of atoms, the initial and final link of which are living organisms. "There is no power on the earth's surface more constantly acting, and therefore more powerful in its final consequences than living organisms as a whole. And the more we study the chemical phenomena of the biosphere, the more we are convinced that there are no cases where they are independent of life. And so it lasted throughout the geological history. $\langle\ldots\rangle$. With the disappearance of life on the earth's surface there would be only slow, hidden from us changes in earth tectonics" (Vernadskii, 2007).

Being the originator of the science of biogeochemistry, V.I. 
Vernadskii formulates three laws (principles) that reflect the geological significance of living matter.

1. Biogenic migration of atoms in the biosphere tends to its maximum manifestation.

2. Evolution of species goes in the direction of increasing biogenic migration of atoms in the biosphere.

3. During the entire geological time, life extends to its maximum possible limits.

Emphasizing the geological significance of living matter, V.I. Vernadskii, at the same time, draws attention to the activity of the thinker's matter - the bearer of cultural biogeochemical energy, a part of living matter capable of accelerating the pace of geological processes through the development of scientific knowledge and socially organized activities directed at it, thereby increasing the value of living matter in the evolution of the biosphere, speeding up its pace.

Thus, living matter and a man act as important factors of geological evolution, which is, in fact, a reflection of the biological evolution. The course and direction of this evolution is associated with the acceleration of the rates of biogenic migration of atoms, which, in turn, contributes to faster rate of evolution of the biosphere.

B. Commoner's environmental laws focus a man on the need for a rational attitude to nature.

These laws are a generalization of existing ecological patterns and are expressed in the form of four aphorisms.

The first Commoner's law. "Everything is connected to everything else."

This law states that any change a man introduces into the world around him can lead to a global catastrophe. The law is based on the principle of positive feedback. According to this principle, any impact beyond the compensatory capacities of the ecosystem leads to its degradation and transition to a new systemic quality. For example, deforestation of tropical forests leads to a decrease in the content of free oxygen in the atmosphere. Reduced concentration of oxygen contributes to the weakening of photochemical ozone synthesis reactions. Thinning of the ozone layer, in the end, leads to an increase in the harmful effect on ultraviolet organisms. B. Commoner notes that "The system stabilizes itself 
due to its dynamic properties, and these same properties under the influence of external loads can lead to dramatic consequences: the complexity of the ecosystem and the speed of its cycle determine the degree of load it can withstand, that is, a slight shift in one place can cause remote, significant and long-term consequences" (Commoner's environmental laws, 2017).

The second Commoner's law. "Everything must go somewhere."

The law states the need to recycle the waste produced by man.

The law is a modification of the physical law of conservation of energy in relation to ecosystems. According to the law, the living nature functions on the basis of closed cycles of matter and energy. Carbon dioxide and water vapor absorbed by the producers are used in the process of biosynthesis of organic matter. Green plants are food for consumers. The remains of organisms are decomposed by the decomposers. The inorganic substance formed by them (nitrogen, phosphorus, carbon dioxide) is again used by producers.

Unlike wildlife, social production is not closed and is associated with the release of unused waste, which "recycling" is impossible or difficult. These waste include plastic, polyethylene, oil, gas, etc. Their accumulation in the biosphere will lead to a disruption of the natural cycles of matter and energy resulting in its selfpoisoning.

The third Commoner's law. "Nature knows best."

This law warns a man against attempts to reorganize ("improve") nature due to the lack in society of sufficient knowledge about the mechanisms of functioning of the biosphere that includes millions of species of living beings and consists of a number of highly complex subsystems.

Indeed, there are many examples where human intervention in natural processes led to unpredictable results. Thus, the shooting of wolves in northern regions of Russia led to outbreaks of infectious diseases among populations of herbivores; mass destruction of sparrows in China contributed to the excessive reproduction of insects, etc.

The fourth Commoner's law. "There is no such thing as a free lunch." The law states the need for rational use of natural resources by man. 
B. Commoner explains this law as follows: "... The global ecosystem is a single whole, within which nothing can be won or lost and that cannot be the object of general improvement: everything that has been extracted from it by human labor must be reimbursed. Payment on this bill cannot be avoided but only delayed. The current crisis in the environment indicates only that the delay has been very protracted" (Commoner's environmental laws, 2017).

In other words, a man, without thinking of using resources and pledging the waste of his economic activity to nature, should think about that someday, his existence will be in jeopardy and he will not have the opportunity to compensate for the harm done to nature.

Thus, the orientation to the environmental laws suggested by $B$. Commoner allows determining the boundaries of human impact on the biosphere, forming ideas about the interrelationship of the components of the ecological chain, and setting the task of preventing the consequences of human irrational activity.

Anthropic cosmological principle and the principle of the Great Cosmological Supplement by
434

Kaznacheev and A.I. Subetto consider a person as a direct participant in the evolutionary processes of the universe.

The founders of the anthropic program (a set of scientific studies aimed at studying the relationship between man and the universe) are R. Dicke and B. Carter, being the first to pose in their works the problem of whether there is a relationship between the fundamental laws of the universe and the conditions of human existence as a being capable of observing it.

The solution to this problem was based on the study of the laws of the chemical evolution of stars. Thus, according to the conclusions by $\mathrm{R}$. Dicke, these laws are strictly consistent with the conditions necessary for the emergence at some stage of their evolution of organic, and, consequently, intelligent life (Dicke, 1961). The consistency of the laws of the evolution of stars with possible emergence of a human being in the universe is at the basis of a weak anthropic principle.

A strong anthropic principle regards a reasonable observer as a certain goal, the sense of the existence of the universe. This version of the anthropic principle is based on anthropic 
arguments - a number of fundamental physical constants, the numerical parameters of which are ideally coordinated with the conditions appropriate for a reasonable life (Carter, 1983; El-Kader, 2018).

Proponents of a strong anthropic principle argue that the universe was originally created for a man and that the very moment of the Big Bang presupposed the emergence of an observer in it. Man in this modification of the anthropic principle is often regarded as the result of some intelligent design (Leslie, 1982).

According to the anthropic principle, the biosphere could not but be "human". Being a part of the selforganizing universe, human activity reflects the logic of development of the objective world, the strategy and trends of its evolutionary changes.

The principle of the Great Cosmological Supplement by Kaznacheev and E.I. Spirin concretizes the concept of a man as a cosmic being, participant in the evolutionary processes of the universe. Here, a person emerges as an element of a self-regulating cosmoplanetary system of the ground, which is the biosphere with its complex solar-terrestrial connections 435 essence of this principle is that any largescale study of the phenomena of the physical world must be correlated with the corresponding studies of living matter and a man as a reasonable form of life." (Kaznacheev \& Spirin, 1991).

Analysis of the anthropic cosmological principle and the principle of cosmological complement allows us to assert that man emerged at a certain stage of the evolution of the Universe, when a combination of fundamental physical constants created conditions for the appearance of intelligent life on the Earth. The presence of reason allows a person to observe and describe the Universe, viewing it in the unity of its matter and material components.

\section{Discussion}

Thus, in the course of the author's study of the conceptual prerequisites for the essential constitution of the philosophy of the biointellectosphere, the following results were obtained:

- Biogeochemical principles of V.I. Vernadskii were considered, the role of living matter and a man as important 
factors in geological evolution was emphasized;

- The environmental laws by B. Commoner were characterized, their significance in the formation of ideas on the interconnection of the components of the ecological chain in determining the boundaries of anthropogenic impact on the biosphere was determined;

- The anthropic cosmological principle and the principle of the Great Cosmological Supplement was analyzed as theoretical generalizations that allow us to view man as a component of the matter and material structure of the Universe, its natural part.

\section{Summary}

Summarizing our research, we can formulate the following conclusions: - a man and living matter are components of the natural organization of the biosphere, the interaction of which determines the course of geological evolution;

- knowing the laws of nature allows a person to determine the boundaries and prevent the consequences of his impact on the biosphere, determine ways to rationalize the forms of economic activity;
- the emergence of mankind is associated with the laws of evolution of the very Universe;

- the evolution of the Universe is a reflection of the unity of man, life and space.

\section{Conclusion}

The materials of the research can be used for further philosophical and theoretical understanding of the prospects of socio-natural development, to develop a strategy for rational interaction between man, society and nature. The results of the work can be also applied to improve the training courses on social philosophy, philosophy of science and technology, and ecology.

During the research, problems were identified that need further elaboration. These include: the need for a deeper understanding of the prerequisites for the emergence of the biointellectosphere in the context of contemporary philosophical and scientific discourses; the definition of the conceptual and substantive foundations of the philosophy of the biointellectosphere; revealing of the essential characteristics of the 
biointellectospheric model of the development of nature and society.

\section{Acknowledgements}

The work is performed according to the Russian Government Program of Competitive Growth of Kazan Federal University.

\section{References}

Smirnov, S. V. (2016). Philosophical Background Setting And Research Problems In Bio-Intellect Sphere. International Journal of Humanities and Cultural Studies (IJHCS) ISSN 2356$5926,3(2)$.

Vernadskii, V. I. (2007). Biosphere and noosphere. - M.: Airis-press,- p. 576.

Kaznacheev, V. P., \& Trofimov, A. V. (2004). Essays on Nature of Living Matter and Intellect on Planet Earth: Problems of Cosmoplanetary Anthropoecology [Ocherki o prirode zhivogo veschestva i intellekta na planete Zemlya: problemy kosmoplanetarnoj antropoekologii].

Subetto, A. I. (2001). Noospherism. Volume one. Introduction to
Noospherism. - St. Petersburg: ON.

Nekrasov KSU, Cyril and Methodius KSU,- p. 537.

Weitzsacker, E. von., Lovins, A. B., \& Lovins L. M. (1997). Factor four Doubling Wealth - halving resours use. A Report to the Club of Rome. London: Earthscan, 322 p.

Sabirov, A. G. (2013). Specific Character and Functional Potential of Social and Humanitarian Cognition Methods. Middle-East Journal of Scientific Research. 17(3), 292-295.

Commoner's environmental laws (2017). [Electronic recourse] http://studbooks.net/37942/ekologiya/za kony_ekologii_kommonera (Accessed date: 28.05 .2017 )

Dicke, R. H. (1961). Dirac's cosmology and Mach's principle. Nature, 192:440441.

Carter, B. (1983). The anthropic principle and its implications for biological evolution. Philosophical Transactions of the Royal Society of 
London. Series A, Mathematical and Physical Sciences, 310(1512), 347-363.

Leslie, J. (1982). Anthropic principle, world ensemble, design. American Philosophical Quarterly, 19(2), 141151.

Kaznacheev, V. P., \& Spirin, E. A. (1991). Cosmoplanetary phenomenon of the human: problems of a comprehensive study. Novosibirsk: Science. Siberian Branch.

Ranjbar haghighi, Y., \& Ghaffari, A. (2016). New Method for Load Balancingin Cloud Computing. UCT Journal of Research in Science, Engineering and Technology, 4(2), 2129.

Abreu, R., David, F., \& Segura, L. (2016). E-banking services: Why fraud is important?. Journal of Information Systems Engineering \& Management, 1(2), 111-121.

https://doi.org/10.20897/lectito.201617 Ekinci, A., \& Ozcan, M. (2017). Levels of Th1 and Th2 Cytokines in Patients with Nasal Polyps. Journal of Clinical and Experimental Investigations, 9(2), 71-75.

El-Kader, S. M. A. (2018). Impact of respiratory muscle training on blood gases and pulmonary function among patients with cervical spinal cord injury. Electronic Journal of General Medicine, 15(3) 